\title{
INDISCIPLINA ESCOLAR: ENTRAVE OU DESAFIO DO COORDENADOR PEDAGÓGICO?
}

\section{INDISCIPLINE SCHOOL: OBSTACLE OR COORDINATOR OF EDUCATIONAL CHALLENGE?}

\author{
Leni Aparecida Souto Miziara (PG-UNESP/Araraquara) \\ Irany Nunes Queiroz (FIPAR)
}

Resumo: Este artigo traz uma reflexão acerca do papel do Coordenador Pedagógico em relação à indisciplina, cujo problema, caracteriza-se como um dos maiores entraves do cotidiano escolar, o que impossibilita os educadores, dentre eles, o coordenador pedagógico de cumprir suas atribuições, sobretudo, no que se refere à formação contínua de professores. Do ponto de vista metodológico, foi adotada a pesquisa qualitativa. Para a coleta de dados, utilizou-se um roteiro de entrevistas semiestruturadas, com questões pertinentes ao trabalho da coordenação de uma escola estadual. Tal estudo chegou à conclusão de que os professores, embora reconheçam o trabalho da Coordenação, não se sentem contemplados no que tange aos aspectos pedagógicos, uma vez que as coordenadoras despendem o tempo na orientação disciplinar dos alunos. Apesar de necessária, esta atuação é insuficiente.

Palavras-chave: Indisciplina. Coordenador Pedagógico. Professor.

Abstract: This article presents a reflection about the role of the pedagogy coordinator in relation to indiscipline, whose problem is characterized as one of the biggest obstacles of everyday school life, which makes the teachers, among them, the pedagogical coordinator to fulfill its mandate, especially regarding the training of teachers. From the methodological point of view, we adopted the qualitative research. To collect the data, we used a itinerary semi-structured interviews, with questions pertaining to the work of the coordination of a state school. This study found that teachers, while acknowledging the work of coordination, do not feel covered in regard to the pedagogical aspects, since the coordinators spend time on the disciplinary orientation of students. Although necessary, this action is insufficient.

Key words: Indiscipline. Pedagogy coordination. Teacher

Não necessitamos de máquinas, sem humanidade. Não necessitamos de inteligência sem amor e ternura. Sem estas virtudes tudo é violência e tudo se perde. (CHARLES CHAPLIN, s/d).

A crise, por certo, contém muitos riscos, mas também oportunidades, porque ela sempre acrisola, purifica e liberta o núcleo de verdades presente nas práticas humanas em crise. Os cenários não de tragédia, mas de libertação [...]. (LEONARDO BOFF, 2002) 


\section{Introdução}

A revolução tecnológica trouxe consigo avanços inauditos, que ao se descortinarem foram introduzindo diversas opções ao nosso caminhar, próprias da utilização indevida do que foi criado para gerar conforto, suprimir desigualdades, melhorar o convívio e as condições existenciais. Exemplificam essa dissonância os meios de comunicação de massa (televisão, rádio, jornais, revistas, propagandas dos mais variados gêneros), quando disponibilizados sem bom senso, deixam de construir. Muitos agem objetivados, segundo a pura concepção de "meios", sem os necessários questionamentos acerca dos fins, com isso, a apaixonante ideia de intensificar informações, democratizar o acesso, facilitar a apropriação de valores, conhecimentos, deixa de existir. No lugar da promoção humana, cria-se o desejo de consumir e conforma-se com o aparente e transitório.

Numa sociedade estruturada no desigual, no descontínuo, essa é a forma mais segura de se instaurar a delinquência. Coisificado, o homem deixa de pensar e sentir por conta própria. A vida fica sem promessas e, paulatinamente, vai se descuidando da imagem positiva de si. Não há entusiasmo quanto à vaidade honesta, ao respeito e à convivência harmoniosa com seus pares. A desapropriação de alguns valores cultivados há séculos, deixa a sociedade sem expectativas para o amanhã. A esse respeito pensa Cortella (2009, p. 19-20).

\footnotetext{
Que modelo de vida é esse que organizamos no ocidente, que nos leva a produzir o maior avanço tecnológico da história da humanidade - nós, HOMO SAPIENS modernos, que tivemos nos últimos 50 anos mais exuberância tecnológica do que nunca - e, ainda assim, o que obtivemos? Um turbinamento do cotidiano, uma aceleração que beira a 'tacocracia', a ditadura do rápido, e, em segundo lugar, uma decepção muito grande... Por vezes, a agente tem uma sensação assim: Isso não está me levando a nada, eu estou indo rápido mas não estou chegando a lugar nenhum.
}

Essa é uma ideia muito forte, por sua vez, nos remete a expressão "círculo vicioso", muito utilizada no Brasil, nas últimas décadas. Ao lado desses indicadores sociais, políticos, econômicos, a família, escola, igreja, emolduradas em estatutos morais, já não convencem. Desalentados, presenciam as transgressões às normas e não raro essas instituições também se veem atingidas na sua organização, na pessoa de seus representantes legais que se vê então a fragilidade dessa nova amostra de homem.

Nesse momento de transição, os desafios são enormes, de modo especial a escola que enfrenta os embates em diversas instâncias, por agregar a pluralidade. Para ela convergem todas as questões acerca de valores. Pode-se dizer, então, que é uma interlocução entre a anomia, heteronomia e autonomia. Essa é uma relevante denúncia. Ademais, é a partir dela que a escola deve estabelecer processos reflexivos e criativos, a fim de focalizar, com maior abrangência, os problemas da indisciplina, ao lado de outros fatores, responsáveis pela queda da qualidade de ensino.

Os paradoxos são tantos que se desencadeia uma crise de encantamento. Fenecem as utopias, o romantismo, a inocência, a integridade e a honra. Analogamente, extinguem-se os sentimentos de pertença. O homem é o cidadão comum! De que mundo?. 
No entanto, a escola pública quer permanecer homogênea, mas a esse respeito o que estava preestabelecido, desmoronou. É claro que esta queda ainda sobrevive a alguns, ainda não se sabe se para o bem ou mal da história. O tempo se encarregará disso.

Na sala de aula, o espaço nobre da escola, tudo isso fervilha e, mergulhados na razão instrumental, nas soluções pragmáticas, no imediatismo do senso comum, todos ficam sem veredas. Surge, então, o "caos". Mas, segundo Morin (2001, p. 13), "é da complexidade que se extrai o novo". Retomando Leonardo Boff (2002), a crise é momento de transformação. $\mathrm{Na}$ escola, todos têm a responsabilidade sobre essas interpretações, contudo, cabe ao Coordenador Pedagógico organizar espaços, tempos para tais reflexões, a fim de verificar se os problemas de indisciplinas têm mesmo como causa as circunstâncias em referência.

O Coordenador Pedagógico jamais teve em mãos um tema tão polêmico e urgente como o da indisciplina. A gravidade da situação subtrai o tempo do Coordenador, de tal forma que esgotado na sua vitalidade, ele não corresponde ao mais específico da sua função - formação contínua dos professores - Esta, conforme Crhistov, (2000) e Placco (2005), auxilia na reflexão da práxis educativa. Acrescenta-se a isto as respostas de algumas professoras entrevistadas numa pesquisa acerca das atribuições do coordenador pedagógico.

Eu trabalho com coordenadoras atuantes e voltadas para o desenvolvimento da criança. Mas às vezes quero saber se há novidades, elas estão atendendo alunos indisciplinados... (BERTA)

Eu estava com problema disciplinar na sala de aula. Então, tive efetivo respaldo da coordenação. (CLAUDIA)

Aqui a coordenação é legal, mas muito ocupada com a indisciplina, quase não tem tempo para nós. (PÂMELA)

As observações das professoras entrevistadas oferecem elementos à busca de ordenamentos mais precisos no que tange à indisciplina, pois se representa o entrave a um desempenho mais completo e abrangente do Coordenador Pedagógico, então, este é o "foco" a ser atingido. Portanto, deve constituir-se em objeto de estudos, pesquisa formação contínua, uma das atribuições do Coordenador Pedagógico. Tratá-la com cientificidade pode ser o início de uma discussão arrazoada capaz de conceder melhorias à qualidade do ensino.

Assim sendo, partimos para uma pesquisa de abordagem qualitativa, tendo como universo investigativo a concepção dos professores em relação ao trabalho da Coordenação Pedagógica. Consoante Minayo (1996), numa pesquisa desta natureza, a entrevista, caracteriza-se como importante meio de possibilitar a compreensão dos conteúdos fornecidos diretamente pelos sujeitos envolvidos no processo. Por isso, a coleta de dados foi por meio de entrevistas semi-estruturadas, na qual foram elencadas questões referentes ao trabalho da Coordenação Pedagógica de uma escola estadual, no município de Paranaíba-MS. 


\section{Concepções dos professores sobre a coordenação pedagógica}

Os pesquisadores em foco (AQUINO, 1996; ARAUJO, 1999; LA TAILLE, 1996; VASCONCELOS,2003; SILVA, 2004) e educadores revelam-se preocupados com os distúrbios disciplinares presente no cotidiano das escolas brasileiras.

A maioria destes autores alerta sobre o risco de se fazer generalizações apressadas e reducionistas sobre este fenômeno.

Discutir indisciplina implica necessariamente envolver aspectos econômicos, culturais, históricos, sociais,

psicológicos e éticas e morais. Nesta abrangência, discutimos o papel da Coordenação Pedagógica frente tal fenômeno a partir dos autores relacionados, com acréscimo de Freire (1986 e 2004), Arroyo (2000), Louro (2002), Morin (2001), Vasconcelos (2006) e Weisz (2002).

Aquino (1996) destaca dois olhares para o conceito de indisciplina: o sócio histórico e o psicológico. No que concerne à análise sócio-histórica, a indisciplina ocorre em virtude do choque entre a escola com seus valores arraigados de subordinação, obediência e militarismo - disciplina por meio de castigo e ameaçasversus o aluno. A escola rejeita admitir este novo aluno possuidor de valores diferentes, com nova configuração social. Ou seja, uma escola planejada para o aluno tradicional e utilizada pelo aluno do século XXI.

O segundo olhar, a ausência de indisciplina é devido à carência psíquica do aluno, do conceito de autoridade e de alguns parâmetros morais essenciais no espaço escolar: conhecimento de regras comuns, cooperação, partilha de responsabilidade e solidariedade. Tais carências podem provocar rebeldia e falta de limites e, normalmente, são derivadas também da incapacidade ou descaso da família em transmitir estes valores à criança. Aquino (1996, p.48) sublinha que

[...] do ponto de vista sócio-histórico a escola é palco de confluência dos movimentos históricos (as formas cristalizadas versus as forças de resistência), [...] e do ponto de visto psicológico ela é profundamente afetada pelas alterações na estruturação familiar.

Para Paulo Freire (2004), a essência de uma educação transformadora reside na dialogicidade. É nesta perspectiva que analisamos o papel da Coordenação Pedagógica e dos professores, pois a dinâmica da sociedade contemporânea nos desafia a alterar sobremaneira as relações humanas, com efeitos que se refletem na política, economia e nos valores sociais. Estas relações são formadoras de uma nova cultura.

Sabemos que este momento é complexo, não obstante é oportuno à Coordenação Pedagógica rever possibilidades de ações concretas, visto que a escola, enquanto espaço político pedagógico, está sempre em conflito. No decorrer da pesquisa de campo vimos, por meio das entrevistas com os professores, o empenho da direção em tentar encaminhar a unidade escolar conforme as normas vigentes, ocasionando assim uma sobrecarga de atividades burocráticas, como: elaboração de documentos, administração financeira e patrimonial, problemas de infra-estrutura, bem como leitura de Diário Oficial, reuniões com outros diretores da cidade e com as supervisoras de gestão escolar.

Quanto às coordenadoras, reconhecemos juntamente com os professores 
entrevistados os seus esforços para atender às diversas demandas do trabalho pedagógico, principalmente no que tange às questões disciplinares, uma vez que a instituição investigada situa-se numa comunidade permeada de violência, desestruturação familiar e exclusão social, com frequência reproduzidas na escola.

Uma das professoras quando entrevistada, comenta que a coordenação desvia a sua função em detrimento de outras atividades, tais como, fazer horário, além de utilizar a maior parte do seu tempo às questões disciplinares. Ela respondeu:

Não justifica, pois o trabalho delas fica muito a desejar. Uma vez que não conseguem acompanhar as atividades desenvolvidas pelos professores. Portanto, ficam sem noção do que passa na sala de aula. (JULIA).

Nesse sentido, faz-se necessário um trabalho consistente ultrapassando os projetos e campanhas pontuais, que, de certa forma, sobrecarregam as coordenadoras, dificultando ainda mais as ações sistematizadas. Além disso, no decurso do ano letivo, existem atividades técnico-burocráticas atinentes não só à atuação do professor em sala de aula, mas também ao funcionamento da escola, nas quais a coordenação apoia o professor: correção de ofícios, diários, bilhetes aos pais, além de relatórios e registro de ocorrências dos imprevistos em sala de aula e de avaliações, como nos exemplos a seguir:

Eu conto com ajuda da coordenação para elaborar os relatórios dos alunos com necessidades especiais, porque acho muito dificil descrever cada situação. (DEISE).

Quando os diários de classe exigiam o relatório do diagnóstico inicial e final, elaborava-os junto com a coordenadora (BERTA.).

Estas atividades ainda que triviais na visão das professoras são imprescindíveis ao trabalho da coordenação, visto que esse momento oferece possibilidades de tomada de consciência sobre como o processo ensino/aprendizagem está se efetivando no cotidiano escolar. Embora inaceitáveis por alguns professores que pretendem dimensionar o papel da coordenação pedagógica apenas como articuladora do trabalho coletivo desenvolvido pela equipe pedagógica. Eis o relato da professora Júlia:

Nesta escola alheia-se do seu papel fundamental. Hoje, eu a vejo o tempo
todo observando a indisciplina de alunos, atividades corriqueiras, assim do
tipo burocráticas, se o professor está dando conta ou não da sala de aula...
mas a questão pedagógica não é trabalhada.

Portanto, as professoras, sujeitos desta pesquisa, não concordam que ações adicionais, alheias ao papel da coordenação pedagógica, sejam uma constante na rotina do trabalho da coordenação, resultando na redução do tempo destinado às atividades inerentes à sua função, cuja essência é coordenar o processo ensino/aprendizagem dos alunos. À vista disso, elas são devoradas pelo imediatismo, pois não lhes sobra tempo frente às urgências do cotidiano escolar: formação contínua, organização de material pedagógico, sessão de estudos, avaliação contínua dos trabalhos desenvolvidos pelos educandos - educadores e, sobretudo o planejamento escolar.

A fala de uma das professoras entrevistadas retrata as atuações das 
coordenadoras, predominantemente direcionadas à resolução de problemas, principalmente disciplinares. Quando questionada sobre em quais momentos procura a coordenação pedagógica, a professora assim se manifestou:

Penso que a coordenação pedagógica deveria trabalhar sempre com os professores no planejamento, acompanhando a sala de aula para observar de perto a defasagem de conteúdos - que, aliás, nesta escola é grande. [...] Deve haver diálogo entre professor e coordenação, embora nem sempre isto seja possivel, porque ela está sempre ocupada com outras atividades, principalmente, com indisciplina. (BERTA).

Sobre o relacionamento entre professor e coordenação da escola:

Eu tento fazer com que seja uma relação cordial, com troca de ideias, e que haja retorno. Embora a coordenação da escola esteja mais preocupada com indisciplina. Elas estão muitas presas a esse controle. Então sobra muito pouco tempo para subsidiar os professores nas suas atividades pedagógicas. (BERTA).

Sobre momentos específicos em que a coordenação pedagógica não atendeu às necessidades, a professora aponta:

Não é que elas não atendem. Às vezes precisamos trocar informações, mas
elas estão resolvendo problemas disciplinares, burocráticos, como, por
exemplo, elaborar oficio para conselho tutelar, conversar com os pais de
alunos que não respeitaram as normas. Quando acabam de resolver aquele,
surge um novo problema, até mesmo dar aula porque faltou professor.
Muitas vezes elas vão para a sala dar aula, vão levar menino ao hospital,
registrar retiradas de livros na biblioteca... Então, a coordenação fica
sobrecarregada com esses problemas, enquanto deveria dedicar-se mais ao
pedagógico. A escola deveria ter funcionário à disposição para tais
atribuiçôes. (BERTA).

Percebemos que esta professora coloca que a função da coordenação fica muito limitada a trabalhar a questão disciplinar dos alunos, ainda que faça parte de suas atribuições, pois esta tem sua parcela de responsabilidade nos conflitos gerados na unidade escolar. Contudo, mais importante do que a questão disciplinar, é fomentar situações que despertem o interesse do aluno, neutralizando a indisciplina. Sem apoio, entretanto, este profissional não consegue "grandes modificações em sua prática pedagógica." (OLIVEIRA, 2002, p.70).

Conversando informalmente com a professora Júlia, ela fez o seguinte apontamento:

Os professores precisam aprender a não pôr alunos fora da sala de aula, pois é isso mesmo que lhes agradam [...]. Nós precisamos fazer o impossível para conquistá-los, em vez de expulsá-los da sala. É ter domínio e não mandar o aluno para a Coordenação. (JULIA).

Dessa forma, a indisciplina, nesta unidade, revela ser um dos problemas mais sérios enfrentados pelos professores, visto que a maioria das professoras entrevistadas queixou-se sobre essa questão.

Geralmente, procuro a coordenação quando tenho problema de indisciplina 
na sala de aula ou preciso falar sobre algum aluno que não está acompanhando, ou está faltoso! (FLÁVIA).

Elas ajudam mais com os problemas indisciplinares. (GLÁUCIA).

Às vezes ficamos cerca de dois, três dias querendo falar com a coordenação pedagógica, e ela ocupada com a indisciplina. Então, é difícil discutir alguma coisa que está incomodando. (OLGA).

Você planeja alguma coisa e chega aqui tem que fazer tudo diferente, devido a eventuais problemas que possam ocorrer; inclusive, na sala que estava agora, tem um engraçadinho (...). (LAÍS).

A Coordenação fica muito envolvida com problemas alheios à sua função. Nesta escola, elas se preocupam muito mais com a indisciplina do pessoal do ginásio, com o professor de ginásio que falta, troca de horário, sobe aula, e nós, do $1^{\circ}$ ao $5^{\circ}$ ano, ficamos a desejar. (KARLA).

A coordenação fugiu do seu papel. Ela não lidera projetos, não observa a didática dos professores. Hoje, está mais voltada ao disciplinar [...]. Elas ficam o tempo todo correndo atrás do comportamento do aluno na sala de aula, ou se o professor domina a sala de aula. (JULIA).

Dou umas broncas, porque tem uns alunos meio “folgados”!!! (ÚRSULA).

Primeiro, organizo a sala, faço-os ficarem mais calmos, porque são muito indisciplinados. (ANNE).

Antes tinha mais paciência, mas hoje, eu os encaminho logo à coordenação: se não quer estudar, então não atrapalha quem quer. (ANNE).

Não sei o que está acontecendo; essa meninada de hoje é terrivel! (JOÃO).

Até que não posso reclamar, controlo bem a indisciplina. (BÁRBARA).

No decorrer das entrevistas, percebemos que, de fato, várias vezes entravam professores ou alunos na sala da Coordenação reclamando das conversas paralelas; discentes que eram encaminhados por incomodarem os demais. Outros fingiam ler, pois estavam fora da sala.

De fato, as diversas formas de indisciplina são o desafio para os educadores que atuam na sala de aula como para os que estão fora - diretores e coordenadores. Segundo Vasconcelos (2007), esse fenômeno ocorre com a mesma proporção tanto na escola pública como na particular. Evidentemente, a escola pública tem se mostrado mais aberta a esta questão. Ela procura sempre parcerias para o melhor encaminhamento dos casos. Por isso, não tem caminhado sozinha: conta com a colaboração do Conselho Tutelar e do Ministério Público, como parceiros, também, responsáveis pelo destino das crianças e dos adolescentes da escola. Ainda segundo Vasconcelos (2007, p. 248),

Sem autoridade não se faz educação; o aluno precisa dela, seja para se orientar, seja para poder opor-se (o conflito com a autoridade é normal, especialmente no adolescente), no processo de constituição de sua personalidade. O que se critica é o autoritarismo, que é a negação da 
verdadeira autoridade, pois se baseia na coisificação, na domesticação do outro.

Face ao exposto, o diálogo com os alunos, pais e professores é a atitude mais constante da coordenação pedagógica visando amenizar o problema. A conquista do aluno, conforme anterior afirmação da professora Júlia, auxilia a melhorar a indisciplina na escola como um todo? Consoante Weisz

[...] numa classe onde professor cultiva a cooperação e o respeito intelectual, eles costumam fazer o mesmo com os colegas. Quando o professor proporciona situações de intercâmbios e colaboração na sala de aula, eles podem trocar informações entre si, discutir de maneira produtiva e solidária e aprender uns com os outros. Para poder explicar para o colega que seu jeito de pensar está incorreto, o aluno precisa formular com precisão e argumentar com clareza - e esta é uma situação muito rica para sistematizar seus próprios conhecimentos. Quando se contradiz e percebe isso, pode reorganizar as ideias, e dessa forma seu conhecimento avança. (WEISZ, 2002, p.72).

Primordialmente, é imprescindível o coletivo da escola (re)pensar uma estratégia conjunta e, nesse sentido, o planejamento é a ferramenta indispensável. Cabe a coordenação pedagógica trabalhar um processo de comprometimento com todos da comunidade de forma substancial. Nesse sentido, Weisz ressalta que "o desejável e necessário é que todos, professores e equipe técnica, se tornem cada vez mais responsáveis, coletivamente, pelo resultado do trabalho de toda a escola." (WEISZ, 2002, p. 123).

Nada resolve a elaboração de medidas repressoras visando a solucionar a questão. É fundamental que se tenha clareza dos fatores geradores das condutas, conhecendo as raízes dos problemas dos alunos vistos como indisciplinados, bem como fazer uma auto-reflexão acerca da prática frente a essas questões. Neste aspecto, Weisz (2002) considera que:

As formas de aprender diferem, que os tempos de aprendizagens também, e que não tem sentido sonhar com todos os alunos caminhando igualmente em seu processo de construção de conhecimento. A igualdade que se defende não se refere ao processo de aprendizagem, mas às condições oferecidas para favorecer a aprendizagem, pois o processo é sempre singular, inevitavelmente. (2002, p. 106).

Portanto, a função do planejamento é "resolver problemas, transformar a prática e, no limite, tornar menor o sofrimento" (VASCONCELOS, 2006, p. 172). Ademais, viabilizar enfrentar o processo de alienação mediante ações intencionais. Há, pois, uma tendência, sobretudo dos professores, em valorizar a prática que nos induz ao imediatismo em detrimento do planejar. Enfim, atuar de qualquer forma, conduzidos pelas pressões rotineiras, é uma tarefa fácil. Complexo é desenvolvermos uma ação consciente, que efetivamente corresponda às necessidades da escola.

Vejamos o depoimento de uma professora entrevistada, quando questionada sobre como é o seu dia-a-dia de trabalho, sua relação com os alunos, colegas:

Primeiramente, faço meu planejamento para a semana toda - prévio. E no dia-a-dia com os alunos, primeiro eu entro, cumprimento a todos e começo a falar sobre o conteúdo, né? Às vezes faço a pauta na lousa. Ah! Posso te confessar uma coisa? Tem dia que esqueço, mas vou levando essa correria 
Esta falta de consciência sobre a importância do planejamento advém, segundo Vasconcelos (2006), da alienação em que se encontra o educador, isto é, o "estado em que as pessoas tornam-se estranhas a si mesmas e ao mundo que as rodeia, não podendo interferir na sua organização, nem sabendo justificar os motivos últimos de suas ações, pensamentos, emoções". (2006, p. 24).

Para esse autor, o trabalho alienado do professor ocorre quando ele ignora o contexto à sua volta, e reduz seu trabalho a uma rotina, objetivando apenas transmitir informações, postura esta que segundo Paulo Freire não condiz com o papel de um educador consciente. "O homem é consciente e, na medida em que conhece, tende a se comprometer com a própria realidade". (FREIRE, 1986, p.39).

Em vista disso, é desafio da coordenação despertar o professor como sujeito reflexivo e transformador, acreditando que tem um papel importante a desempenhar em parceria com os demais educadores e pais. Consoante Weisz (2002, p. 117):

[...] a atividade de ensino do professor vai ter de dialogar com a atividade de aprendizagem do aluno. Para isso ele vai precisar considerar muitas variáveis e tomar outras tantas decisões, o que equivale a assumir um alto grau de autonomia. Para dar conta dessa nova demanda é preciso condições de desenvolvimento profissional e de qualificação diferentes das que vêm sendo oferecidas, no geral, aos professores.

A professora Júlia sublinha a preocupação com a qualidade do serviço prestado pelos colegas. Atesta a dificuldade que é desenvolver um trabalho coletivo, uma vez que a maioria não se preocupa em desempenhar bem o seu papel mediante $o$ autoquestionamento, reconhecendo os limites de sua competência e formação. Vejamos o depoimento dela:

Analisando a nossa escola, constatamos que a educação está do jeito que está por falta de boa vontade, principalmente dos professores. Esta é minha opinião. Porque a gente analisa o seguinte: são poucos os professores que preparam uma boa aula, que vão atrás de alguma atividade interessante, que motivam seus alunos. São raros os que dão aula em pé, que vão atrás de atividades diferentes para o aluno(...) Professor, hoje, muitas vezes senta e dali só lê, manda fazer um questionário, uma atividade e dá uma notinha pra, como se diz, "eu fiz alguma coisa, está aqui o meu trabalho". (...) E não é por aí (...) Outro dia mesmo, estava conversando com uma professora da UFMS e ela me disse: - Olha Júlia, tem professor que não tem nem conhecimento dos PCNS(...) Então se a gente ler, estudar realmente, conseguiremos fazer um bom trabalho. (...) Quando fala em um trabalho interdisciplinar, a maioria não sabe trabalhar. Eu mesma tenho dificuldade em desenvolver projeto na escola porque, quando se em fala projeto, significa um todo, ou seja, todo mundo tem que trabalhar de uma forma ou de outra, tem que estar contribuindo. E na verdade isso não acontece. Ele acaba sendo só da gente, não conseguimos envolver 100\% dos alunos,

muitas vezes por falta de motivação de outro professor, que não acredita naquilo, acha que não vai dar certo. (...) O projeto não é uma coisa que terá efeito imediato, tudo é em longo prazo (..).Então, caso todos os professores realmente cumprissem o seu papel de professor, se empenhassem mais, com mais vontade de trabalhar, de fazer com que o aluno aprenda, poderíamos mudar a educação. Mas infelizmente, na escola pública, nosso trabalho é todo fragmentado: eu dou o que acho que está certo, o outro também, enfim 
Notamos que a professora identifica pouca cumplicidade no trabalho dos colegas, dificultando, portanto, o encaminhamento de um trabalho coletivo e transformador. E, neste caso, impregna o ambiente escolar, "levando-o ao sofrimento, ao desgaste, ao desânimo, ao descrédito quanto à educação, à acomodação, à desconfiança, chegando mesmo à falta de companheirismo e de engajamento em lutas políticas e até sindicais." (VASCONCELOS, 2006, p. 25).

Dessa forma, os professores se veem praticando um ritual que não apresenta efetivos resultados na prática cotidiana. Nessa abrangência, foi comovente o relato da professora Laís, pois no momento da entrevista expressava decepção e muita vontade de trabalhar de forma planejada juntamente com seus colegas.

\begin{abstract}
No início de todo ano é uma maravilha, saímos daqui com a cabeça cheia, imaginando que iremos trabalhar tanto! (...) A coordenação aponta tantos projetos junto com os professores... enfim, tudo o que irá acontecer na escola com muito entusiasmo. (...) E agora, já estamos em maio e não fizemos nada. Infelizmente propõe-se muito, mas fica correndo solto, não se consegue levar em frente as ideias. Nossa! É muito complicado! A princípio pensamos que ficaremos na escola até aos domingos, de repente não sabemos como finalizar o ano. (LAÍS).
\end{abstract}

Nesse momento, é importante trazer à tona, o apregoado por Arroyo (2000) ao afirmar que é papel da coordenação trabalhar os conflitos entre docentes, visto que, há interesses muito diversos na categoria do magistério. Por exemplo, quando nos aproximamos das redes de ensino, ou participamos da elaboração e implementação de uma proposta pedagógica, percebemos como os interesses da categoria são diversos na concepção e prática de Educação Básica. "Descobrimos fragmentos. Cacos de uma unidade quebrada. Cacos difíceis de colar até nos momentos de inovação pedagógica". (ARROYO, 2000, p. 217).

Sem dúvida, o planejamento é uma diretriz das metas propostas. Nesta escola, contudo, fomenta-se um plano e, no decurso do ano letivo, a coordenação, voltada para outras atribuições, não prioriza o seu desenvolvimento. Aliás, percebemos pelo desabafo da professora Laís que a proposta de trabalhar por meio de projetos é um dos quesitos desacreditados nesta instituição: "as ideias são postas com entusiasmo pelas coordenadoras e, posteriormente, quase nada se conclui". (LAIS).

Não basta ter uma finalidade inicial, é preciso que ela acompanhe a atividade de concretização, ainda que o resultado - em função de fatores intervenientes - saia diferente do ideal inicial. "A realização do planejado não vai se dar de forma linear, mas por um processo de aproximações sucessivas”. (VASCONCELOS, 2006, p. 87). O desafio, portanto, está em fazer com que os profissionais envolvidos percebam a necessidade da construção de uma Proposta Político-Pedagógica, e que esta garanta a construção da unidade e dinamismo para que a escola promova uma aprendizagem comprometida com a emancipação dos alunos.

Vimos nos apontamentos das professoras que o maior problema da instituição, de um modo geral, é a carência de tempo da coordenação no que concerne ao planejamento e respaldo pedagógico. Todavia tanto a professora Júlia como as demais educadoras entrevistadas, revelaram-se preocupadas em planejar suas aulas de forma 
prazerosa para despertar a atenção dos alunos e por consequência diminuir a indisciplina.

\begin{abstract}
Organizo minhas aulas com dinâmicas. Não fico apenas no conteúdo: utilizo poesias, teatro, música e filmes, mas não qualquer um, só para enrolar o tempo. (PÂMELA).

$\mathrm{Na}$ verdade, meu dia de trabalho começa um dia antes (risos), porque não vou para a sala de aula sem planejar. Então, um final de semana antes, vejo os conteúdos que vou trabalhar, e a partir daí, procuro atividades diferentes. Na minha cabeça, a aula começa no dia anterior ou talvez um final de semana antes, dependendo de como será a correria da semana. Aliás, se não tivermos organização, perdemos muito tempo. (CLÁUDIA).
\end{abstract}

Essas professoras veem o planejamento como sistematização do fazer pedagógico. E, neste caso, são cônscias de sua importância para uma ação eficaz. No entanto, esse instrumento precisa estar vinculado à Proposta Pedagógica da Escola, na qual, por sua vez, devem constar as diretrizes e concepções defendidas pela instituição. Com base nas entrevistas coletadas, reconhecemos nas coordenadoras, uma preocupação em assessorar todos os segmentos da unidade escolar. Contudo, faltamlhes condições para exercer alguns trabalhos inerentes deste oficio, haja vista que, se ela desejar reunir os professores por área, por exemplo, não conseguirá - porque eles têm uma sobrecarga de trabalho; ou se quiser dispensar os alunos para um trabalho de formação, as supervisoras de gestão escolar, respaldadas pela legislação, não permitirão. Face a esse panorama, a coordenação não delineia, de maneira autônoma, nem mesmo o seu próprio projeto de ação, e segue cumprindo o seu papel de forma tarefeira, com poucas condições de efetuar trabalhos como os de formação contínua ou ainda, de planejamento que são próprios de sua função.

Além disso, as educadoras entrevistadas atribuíram como causa da indisciplina a falta de tempo e afeto dos pais. Mas como resolver esta situação se estes precisam ausentar-se o dia inteiro, ou toda a semana, para trazer para casa o sustento da prole?

\begin{abstract}
Hoje, não temos o mesmo respaldo de quando comecei minha carreira. É muito complicado, pois devido à indisciplina dos alunos, ficamos trabalhando mais a formação moral e ética do que o conteúdo. Temos muitas vezes que fazer o papel de pai e mãe. Isso me aborrece porque dificulta o trabalho, isto é, perco tempo chamando atenção de menino. (ANNE).
\end{abstract}

Essa professora mencionou os males provocados pela falta dos pais na educação dos filhos, uma vez que os valores básicos na formação do ser humano, a princípio, são transmitidos por eles. De certa forma, isso não se trata de negligência dos pais, e sim do ritmo de vida frenético, que consome o tempo do adulto de tal maneira que ele se vê sem tempo para o filho - então permite tudo para compensar a ausência, que os deixa com sentimento de culpa. Contudo, quando há parceria entre escola e família é possível amenizar esta defasagem de limites na vida das crianças e adolescentes. Nesse caso,

ambas precisam rever as linhas estabelecidas que orientam e organizam o tempo e o espaço.

La Taille (1996) aponta caminhos de como a escola pode discutir princípios e valores. Para ele, antes de qualquer atitude, a escola precisa definir seus próprios princípios de acordo com a Constituição brasileira: liberdade, respeito, igualdade, 
justiça, dignidade. Deixando-os claro aos pais e alunos. Quando um destes for ferido a equipe pedagógica deve debatê-lo, se possível, em assembleia para discutir as regras que garantem a defesa do principio. "A dimensão moral da criança tem de ser trabalhada desde a Educação Infantil. Ética se aprende, não é uma coisa espontânea." (LA TAILLE, 1996, p.71). Ademais, é importante que os educadores lembrem de que o aluno possui hábitos e atitudes aprendidos no seu meio social que são aceitos naturalmente por eles. E, esse comportamento às vezes é considerado, pelos professores, como rebelde, grosseiro, violento. Isso ocorre devido a criança comportar-se a seu estilo, pois desconhece certos princípios da instituição e pelo fato do professor ignorar a realidade do aluno.

Nesse sentido, Freire (2004) assinala que esta resistência do professor em respeitar a "leitura do mundo" com que o aluno chega à escola, evidentemente condicionada pela cultura do seu grupo social e revelada em sua linguagem se constitui em um obstáculo ao conhecimento. Ou seja, além de todo o conflito que a diferença social e cultural causa na relação professor-aluno, ainda há o agravante de dificultar o aprendizado, já que na tarefa de ensinar, o professor não parte da realidade concreta dos educandos e da experiência de vida deles.

Achamos interessante registrar aqui a discordância de uma das professora sobre as normas instituídas pela escola para a acolhida dos alunos.

Quando chego, recolho meus alunos na fila - o que eu acho uma aberração, não gosto desta fila, mas tenho que cumprir ordens. Na sala, eles se sentam em lugares determinados. Arrumo a sala em forma de U, porque o espaço fica melhor, e posso ver os rostinhos de cada um, e eles me veem também. Fazemos nossa oração e depois nós começamos a trabalhar. (ANNE)

É preciso lembrar que os espaços escolares, bem como outros pelos quais circulamos, não são neutros, mas produzidos através de investimentos de caráter disciplinar e ordenador. (LOURO, 2002). Segundo esta autora, os alunos

[...] distribuídos, ainda hoje, nas filas de entrada - uma para os meninos e outra para as meninas - por turma e, muitas vezes, por altura, devem 'guardar distância'entre uns e outros, não se amontoando ou se tocando. Aos sinais da companhia, ou sineta - deslocam-se (espera-se que em ordem) para suas salas, ocupam suas carteiras, devem ficar sentados/as e preferentemente em silêncio a maior parte do tempo. As matérias se sucedem frequentemente em períodos iguais. A uma hora previamente determinada e marcada no relógio escolar, saem para o recreio, onde são estimulados a se ocuparem de jogos ou brincadeiras diferentes. Voltam às aulas, sentam-se novamente e, algumas vezes, se organizam em grupos para atividades, quando, então, é-lhes permitido juntar as carteiras (para o que, apesar dos esforços, geralmente farão algum barulho). Se essas ações parecem indicar algumas alterações no tempo e no espaço escolar, um olhar mais atento revelará que as brincadeiras, as filas ou os grupos se arranjam 'naturalmente', aproximando aqueles e

aquelas que se veem como 'iguais' - os meninos brincam e trabalham separados das meninas, os/as 'adiantados/as' afastam-se dos/as que possuem todo o 'material', evitam compartilhá-lo com quem não o tem. (LOURO, 2002, p. 123).

A contribuição da autora possibilita compreender que os professores prepararam 
atividades visando preencher o tempo das crianças de forma homogênea: os alunos são submetidos às mesmas tarefas a serem cumpridas num mesmo espaço de tempo. Pois, a insistência da escola em negar as diferentes relações que as crianças e adolescentes estabelecem com o tempo, faz com que seja instituída uma rotina, e esta dificulta as possibilidades de sucesso, movimento e alegria. Por certo, enquanto a escola exigir de todos os alunos a mesma capacidade e ritmo, eles responderão com indisciplina, ocasionando aborrecimentos, além de consumir o tempo pedagógico. Conforme nos lembra Louro:

É pela imposição de um ritmo próprio, escolar, marcado por sinais (como sinetas, gestos e olhares dos/as professores/as etc), e pela delimitação do que pertence à sala de aula e o que fica fora dela, que se treinam os sujeitos para aquisição de uma postura e uma disposição vistas como condizentes às atividades intelectuais e reflexivas. (LOURO, 2002, p. 126).

Assim, sair da rotina e procurar formas diversas de motivação não é tarefa fácil, uma vez que implica mudança não só de atitudes individuais como também de toda a equipe pedagógica da escola. Por isso, pensar tempos necessários a uma ação pedagógica significa fortalecer o trabalho coletivo, compatibilizando estes momentos com projetos que atendam às necessidades de formação dos alunos consoante princípios da Escola.

Isso não significa, no entanto, que salientar a importância deste tempo, enquanto espaço de formação profissional, seja algo meramente repetitivo. Algumas ações relatadas pelas professoras no interior da escola evidenciam processos formativos que não acontecem isoladamente, mas em parceria com os diferentes atores envolvidos no espaço educativo. Nesse sentido, convém lembrar-se do apelo de Paulo Freire:

Tudo que a gente puder fazer no sentido de convocar os que vivem em torno da escola, e dentro da escola, no sentido de participarem, de tomarem um pouco o destino da escola na mão, também. Tudo o que a gente puder fazer nesse sentido é pouco ainda, considerando o trabalho imenso que se põe diante de nós que é o de assumir esse país democraticamente. (FREIRE, 1986, p.36).

Assim sendo, para atender a esse desafio, é imprescindível que o coletivo da instituição, liderado pela coordenação, conquiste um tempo não tarefeiro e, sobretudo, que suas ações no planejamento tenham em sua essência a ideia de transformação social.

\section{Considerações Finais}

Diante do exposto, percebe-se que a maioria das professoras investigadas reconhece a importância do papel da coordenação, contudo, não se sentem contempladas no tocante aos aspectos político-pedagógicos, visto que as coordenadoras empregam muito tempo na repreensão dos alunos. Portanto, a indisciplina constitui um dos graves problemas que a escola enfrenta. Neste caso, segundo as professoras, inviabiliza a atuação pedagógica.

As educadoras entrevistadas ressaltaram outras dificuldades que comprometem as ações da coordenação no processo ensino-aprendizagem: sobrecarga de trabalho com 
atividades triviais que poderiam ser delegadas a outros funcionários da instituição. Dessa forma, os dados empíricos deste estudo permitem sublinhar que as coordenadoras são atropeladas por múltiplas solicitações, emergências e imprevistos provocados principalmente pela indisciplina na sala de aula. Estes entraves dificultam o desenvolvimento das atividades destinadas especificamente aos aspectos didáticos dos conteúdos escolares e à formação contínua dos educadores.

Após análise dos autores consultados e os depoimentos dos sujeitos desta pesquisa, podemos responder de maneira convicta ao questionamento do título deste artigo: Indisciplina Escolar: Entrave ou desafio do Coordenador Pedagógico? Embora os depoimentos dos professores demonstrem que a indisciplina se constitua num entrave na rotina dos coordenadores, ela pode, contudo, ser enfrentada como um desafio que se bem interpretado pela equipe gestora esta poderá mediar à construção da autonomia moral por meio de formação destinada a este fim, a qual deve contemplar todos os segmentos da unidade escolar.

Esta tarefa, prioridade do momento, exige dos coordenadores o conhecimento teórico, rigor na sistematização das ações a fim de promover o debate pedagógico com mais intensidade junto ao coletivo da escola neste momento de transição paradigmática.

Assim, os problemas disciplinares responsáveis por reduzir em grande parte o tempo dos coordenadores pedagógicos serão paulatinamente superados por meio de um processo ensino e aprendizagem mais dinâmico, crítico e significativo para alunos e professores. Portanto, envolver todos os segmentos da escola em torno desta reflexão é avançar com maior segurança rumo a transformação da sociedade, meta imprescindível da coordenação.

\section{Referências:}

ARAÚJO, U. F. Moralidade e indisciplina: uma leitura possível a partir do referencial piagetiano. Anais da Jornada Paranaense de Educação... Londrina: Futuro Eventos. 1999, p. 40-48.

ARROYO, Miguel G. Ofício de Mestre: Imagens e auto-imagens. Petrópolis: Vozes, 2000 .

AQUINO, J. G. Indisciplina na escola: alternativas práticas e teóricas. São Paulo: Summus, 1996.

BOFF, Leonardo. Crise de Oportunidade de Crescimento. Campinas: Verus, 2002

CORTELLA, Mario Sergio e LA TAILlE, Yves. Nos labirintos da Moral. Campinas: Papirus, 2009.

CHRISTOV, Luiza Helena da Silva. Educação Continuada: função essencial do coordenador pedagógico. In: GUIMARÃES, Ana Archangelo. et al. O coordenador pedagógico e a educação continuada. 4. ed. São Paulo: Loyola, 2000. p. 9-12.

FREIRE, Paulo. Educação e Mudança. 11. ed. Rio de Janeiro. Paz e Terra, 1986. 
Pedagogia da autonomia: saberes necessários à prática educativa. 16 ed. São Paulo: Paz e Terra, 2004.

LA TAILLE, Y. A indisciplina e o sentimento de vergonha. In: AQUINO, J. G. (Org.). Indisciplina na Escola. São Paulo: Summus, 1996.

LOURO, Lopes Guacira. A escola e a pluralidade dos tempos e espaços. In. COSTA, Marisa Vorraber (org). Escola Básica na virada do século: Cultura, Política e Currículo. 3.ed. São Paulo: 2002. p.119-129

MINAYO, Maria Cecília S. (Org). Pesquisa social: teoria, método e criatividade. 23 ed. Petrópolis, RJ: Vozes, 1996.

MORIN, E. Os sete saberes necessários à educação do futuro. São Paulo: Cortez: Unesco, 2001.

OLIVEIRA, M.K. Psicologia, Educação e as Temáticas da Vida Contemporânea. São Paulo: Moderna, 2002.

PLACCO, Vera Maria Nigro de Souza; SILVA, Sylvia Helena Souza da Silva. A formação do professor: reflexões, desafios, perspectivas. In: BRUNO, Eliane Bambini

Gorgueira; ALMEIDA, Laurinda Ramalho de; CHRISTOV, Luiz Helena da Silva (Orgs.). O Coordenador pedagógico e a formação docente. 6 ed. São Paulo: Loyola, 2005. p.25-32

SILVA, N. P. Ética, Indisciplina \& Violência nas Escolas. Petrópolis: Vozes, 2004.

TELES, Maria Luiza Silveira. Filosofia para crianças e Adolescentes. Petrópolis: Vozes, 1999.

VASCONCELLOS, Celso dos S. Planejamento: Projeto de ensino-aprendizagem e o projeto político-pedagógico. 16 ed. São Paulo: Libertad, 2006.

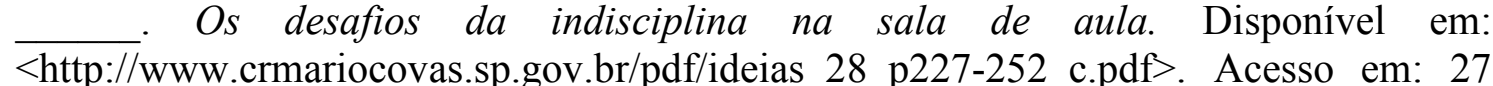
set. 2007.

VASCONCELOS. M. S. Disciplina e indisciplina como representações na educação Contemporânea. In: LEITE, R. L. Formação de Professores: desafios e perspectivas. São Paulo: Unesp, 2003. p 465 - 479

WEISZ, Telma. O diálogo entre o ensino e a aprendizagem. São Paulo: Ática, 2002. 